\title{
Support for removal of point-of-purchase tobacco advertising and displays: findings from the International Tobacco Control (ITC) Canada survey
}

\author{
Abraham Brown, ${ }^{1,2}$ Christian Boudreau, ${ }^{3}$ Crawford Moodie, ${ }^{1}$ Geoffrey T Fong, ${ }^{4,5}$ \\ Grace Y Li, ${ }^{6}$ Ann McNeill, ${ }^{2}$ Mary E Thompson, ${ }^{3}$ Louise M Hassan, ${ }^{7}$ Andrew Hyland, ${ }^{8}$ \\ James $\mathrm{F}$ Thrasher, ${ }^{9,10}$ Hua-Hie Yong, ${ }^{11}$ Ron Borland, ${ }^{11}$ Gerard Hastings, ${ }^{1}$ \\ David Hammond ${ }^{12}$
}

${ }^{1}$ Centre for Tobacco Control Research, Institute for Social Marketing, University of Stirling, Stirling, UK

${ }^{2} U K$ Centre for Tobacco Control Studies, Division of Epidemiology and Public Health, Clinical Sciences Building, University of Nottingham, Nottingham, UK

${ }^{3}$ Department of Statistics and Actuarial Science, University of Waterloo, Ontario, Canada ${ }^{4}$ Department of Psychology, University of Waterloo, Ontario, Canada

${ }^{5}$ Ontario Institute for Cancer Research, Ontario, Canada ${ }^{6}$ Propel Centre for Population Health Impact, University of Waterloo, Ontario, Canada 'Lancaster University Management School, Lancaster, UK

${ }^{8}$ Department of Health Behavior, Roswell Park Cancer Institute, Buffalo, New York, USA

${ }^{9}$ Department of Health Promotion, Education and Behavior, Arnold School of Public Health, University of South Carolina, Columbia, SC, USA

${ }^{10}$ Department of Tobacco Research, Center for Population Health Research, National Institute of Public Health, Cuernavaca, México

${ }^{11}$ VicHealth Centre for Tobacco Control, Cancer Council Victoria, Carlton, Australia

${ }^{12}$ School of Public Health and Health Systems, University of Waterloo, Ontario, Canada

\section{Correspondence to} Dr Abraham Brown, Centre for Tobacco Control Research, Institute for Social Marketing, University of Stirling, Stirling FK9 4LA, UK; akb2@stir.ac.uk

Received 20 July 2011 Accepted 7 September 2011

Published Online First 15 October 2012

\begin{abstract}
Background Although most countries now have at least some restrictions on tobacco marketing, the tobacco industry meet these restrictions by re-allocating expenditure to unregulated channels, such as at point-of-purchase.

Methods Longitudinal data from 10 Canadian provinces in the International Tobacco Control Survey was analysed to examine adult smokers' support for a ban on tobacco advertising and displays in stores and whether this support is associated with noticing either advertising or displays in stores, and quit intentions, over time. In total, there were 4580 respondents in wave 5 (October 2006 to February 2007), wave 6 (September 2007 to February 2008) and wave 7 (October 2008 to June 2009). The surveys were conducted before, during and in some cases after the implementation of display bans in most Canadian provinces and territories.
\end{abstract}

Results Smokers in all provinces showed strong support for a ban on tobacco displays over the study period. Levels of support for an advertising and display ban were comparable between Canadian provinces over time, irrespective of whether they had been banned or not. Noticing tobacco displays and signs in-store was demonstrably less likely to predict support for displays $(\mathrm{OR}=0.73, \mathrm{p}=0.005)$ and advertising $(\mathrm{OR}=0.78$, $\mathrm{p}=0.02$ ) ban, respectively. Smokers intending to quit were more likely to support advertising and display bans over time.

Conclusion This study serves as a timely reminder that the implementation of tobacco control measures, such as the removal of tobacco displays, appear to sustain support among smokers, those most likely to oppose such measures.

\section{INTRODUCTION}

For decades, tobacco marketing has been used to portray tobacco use in a favourable light, normalise smoking, underplay the associated health risks and ultimately undermine tobacco control efforts. ${ }^{1}{ }^{2}$ The Framework Convention on Tobacco Control, ${ }^{3}$ currently with 172 signatories covering almost 90\% of the global population, obligates member parties to introduce comprehensive bans on tobacco marketing. The need for bans to be comprehensive is based on evidence that the tobacco industry adeptly exploits unregulated channels, such as at point-of-purchase (POP), to maintain and even increase consumption. ${ }^{4} 5$

POP marketing includes advertising as well as displays of tobacco products on, behind and above the service counter. Displays in particular increase exposure to tobacco products and normalise tobacco use, especially for young people. ${ }^{467}$ They also provide powerful cues to smoke ${ }^{89}$ and stimulate impulse purchases among adult smokers, recent quitters and those intending to quit. ${ }^{8} 10-13$ The effectiveness of displays at POP helps explain why the tobacco industry have increased marketing expenditure within the retail environment, especially when other marketing channels have been closed off to them. ${ }^{514}$

The tobacco industry vehemently opposes the removal of POP advertising and particularly product displays, presumably as they are aware of their importance as marketing tools. ${ }^{8} 13$ As displays remain one of the few viable means for promoting tobacco products, understanding the level of support for their removal among smokers, the group most likely to be opposed to such restrictions, and whether support is associated with quit intentions can help inform tobacco control policy. To date, however, research assessing smokers support for the removal of tobacco advertising and displays within shops, and intention to quit, remains scarce, whether in countries that have banned displays or are yet to do so. ${ }^{13-15}$

In Canada, although the Tobacco Act 1997 banned various forms of tobacco marketing, instore advertising such as portrayals of signs that indicate the availability of tobacco products and their prices were permitted. ${ }^{16}$ In accordance with the regulations, tobacco products or accessories that display a tobacco-related brand may be allowed at retail outlets. Nonetheless, since 2002 several provinces and territories have passed laws requiring the removal of tobacco displays and associated advertising, despite strong opposition from the tobacco and retail industries predicting that the move to 'out of sight' tobacco sales would drive retailers out of business, a finding not substantiated by the evidence. ${ }^{17}$

Research in Ireland showed that at a population level, support for a display ban increased over a 9-month period before and after implementing the policy. ${ }^{14}$ This study, and other research, indicates smokers to be supportive of display bans 
because these displays are considered to have promotional appeal $^{18}$ that may provide visual cues to would-be starters and recent quitters. ${ }^{8} 18$ A recent cross-sectional study found that four times as many smokers were supportive of a ban on displays than were unsupportive (49\% vs $12 \%){ }^{5}$ No research, however, has empirically examined, over a longer time period, whether the introduction of a display ban is associated with an increase in support or whether support is associated with quitting behaviour, as we have seen for smoke-free policies. We extend existing research by examining whether adult smokers' support for the removal of tobacco advertising and displays in stores has increased between 2006 and 2009 in 10 Canadian provinces, where they have been removed before, during and after the study period.

This paper addresses three research questions: (1) What was the impact of the ban on tobacco displays in several Canadian provinces on smokers' support for such a ban over time? (2) Did noticing tobacco displays and signs in stores predict support for a ban on advertising and displays over time? and (3) What are the associations between intentions to quit and support for a ban on advertising and displays at POP?

\section{METHODS}

\section{Data and analytic sample}

The International Tobacco Control Four Country Survey is a quasi-experimental longitudinal telephone survey conducted annually with nationally representative samples of adult smokers aged 18 years or older in Canada, the USA, the UK and Australia. The survey is designed to evaluate the psychosocial and behavioural impact of key national-level tobacco policies in these four countries over time.

Participants are recruited by geographically stratified probability sampling, with telephone numbers selected at random in each country. Eligible households are identified by asking a household informant the number of adult smokers within the household, with smokers defined as having smoked $>100$ cigarettes in their life and at least once in the past 30 days. Where there was more than one eligible respondent, the next birthday method was used to select the target respondent in that household. ${ }^{20}$ In order to maintain a sample size of at least 2000 within each country, replenishment is used each year to replace those lost to attrition, using random sampling from the same sampling frame. A full description of the methodology and sampling procedure can be found elsewhere. ${ }^{19} 21$

This study presents data from wave 5 (October 2006 to February 2007), wave 6 (September 2007 to February 2008) and wave 7 (October 2008 to June 2009). We used all available respondents that participated at one or more of the three waves. A total of 4580 respondents comprising only smokers from 10 Canada provinces were used for this study. We focus exclusively on Canada and do not include Australia, the UK or the USA, given that only in Canada had some provinces and territories actually banned the display of tobacco products during the study period. All Australian states and territories have now passed legislation to move tobacco out of sight in general retail stores by January 2012, and the Scottish and English governments plan to do likewise in large shops and supermarkets by April 2012.

The implementation of the ban on tobacco displays in the 10 Canadian provinces occurred before, during and after the study period. Consequently, the 10 provinces were categorised into five zones to reflect provinces that had fully implemented a display ban prior to (zone 1), during (zones 2, 3 and 4) and after (zone 5) the study period (table 1 ). This permitted comparisons of provinces that had banned in-store displays and advertising before and
Table 1 Implementation dates of bans on the display of tobacco at point-of-purchase in Canadian Provinces and Territories

\begin{tabular}{llll}
\hline Jurisdiction & Date of implementation & Zone & Period \\
\hline Manitoba & 1 January 2004 & 1 & Pre \\
Nunavut & 1 February 2004 & 1 & Pre \\
Saskatchewan & 1 January 2005* & 1 & Pre \\
Prince Edward Island & 1 June 2006 & 1 & Pre \\
Wave 5 & 2006/2007 & & \\
$\quad$ Northwest Territories & 21 January 2007 & 2 & Mid \\
$\quad$ Nova Scotia & 31 March 2007 & 2 & Mid \\
Wave 6 & 2007/2008 & & \\
$\quad$ British Columbia & 31 March 2008 & 3 & Mid \\
Ontario & 31 May 2008 & 3 & Mid \\
Ouebec & 31 May 2008 & 3 & Mid \\
$\quad$ Alberta & 1 July 2008 & 3 & Mid \\
New Brunswick & 1 January 2009 & 4 & Mid \\
$\quad$ Yukon & 15 May 2009 & 4 & Mid \\
Wave 7 & 2008/2009 & & \\
$\quad$ Newfoundland and Labrador & 1 January 2010 & 5 & Post \\
\hline
\end{tabular}

NB: Three Canadian territories (Nunavut, Yukon, and Northwest Territories) were excluded in the analysis because of small population size.

*Saskatchewan legislation banned retail displays of tobacco in 2002, but this was declared invalid because of a challenge by the tobacco industry. However, the Supreme Court of Canada unanimously upheld the constitutionality of the legislation in January 2005.

during the study period (classified as the treatment groups), with provinces that had not banned the display of tobacco at POP (classified as the control groups). Three Canadian territories (Yukon, Nunavut and Northwest Territories) were not included in the analysis because they have an average of 35000 people (each territory has $0.1 \%$ of the total population of Canada).

The study was approved by the Institutional Review Board or Research Ethics Board at the University of Stirling (Scotland), the Open University (UK), University of Waterloo (Canada), Roswell Park Cancer Institute (USA), University of Illinois, Chicago (USA), and The Cancer Council Victoria (Australia).

\section{MEASURES}

\section{Outcome measures: support for bans on POP advertising and displays}

Two items were employed to measure support for a ban on POP advertising and displays: "Do you support complete bans on tobacco advertisements inside shops and stores?" and "Do you support complete bans on displays of cigarettes inside shops and stores?" Both were measured on a 3-point scale with the response options 'A lot', 'Somewhat' and 'Not at all'. For the Generalised Estimating Equations (GEE) analyses, this 3-point scale was dichotomised to give: support for complete bans (A lot, Somewhat) vs does not support complete bans (Not at all).

\section{Intention to quit}

A 4-point scale that measured readiness to quit ${ }^{22} 23$ was dichotomised to compare smokers with any intention to quit and those without.

\section{Covariates}

Covariates included were: zones (between Canadian zones comparisons), wave (5* vs 6 vs 7 ), gender (male* vs female), ethnicity (Caucasian vs other*), age (18-24 vs $25-39$ vs $40-54$ vs $55+^{*}$ ), income (low vs moderate vs high ${ }^{*}$ ) and education (low vs moderate vs high*), where * indicates the baseline or reference level. Consistent with Borland et al's ${ }^{24}$ study, a heaviness of smoking index combined responses about cigarettes per day and time to first cigarette (range $0-6$ ). In addition, two interactions of main interest being zone $x$ wave and education $\times$ income were considered. 
Respondents were also asked two specific questions about their awareness of tobacco displays and signs in stores or shops: "In the last month, have you seen cigarette packages being displayed, including on shelves or on the counter?" and "In the last month, have you seen any signs or pictures or other things like clocks with cigarette brands or logos inside shops or stores?" Response to both was dichotomised as 'yes' (coded as 1) or 'no' (coded as 0).

\section{SURVEY WEIGHTS}

Cross-sectional survey weights were computed for respondents using reciprocals of inclusion probabilities. Departures from proportional allocation to geographic strata over time were adjusted for and calibrated to sum to numbers of smokers in age-sex groups. Hence, respondents are weighted to be representative of the adult smoker population in each province. Respondents that completed the follow-up surveys (ie, waves 6 and 7) had their baseline weights (wave 5) adjusted for attrition. ${ }^{21}$ All analyses described in this paper are weighted.

\section{DATA ANALYSIS}

Analyses were conducted using SAS 9.2, a statistical software. $\mathrm{GEE}^{25-27}$ were used to examine whether smokers' support for removal of advertising and displays at $\mathrm{POP}$ changed over time (waves 5, 6 and 7). GEE models were assessed via binomial variations and the logit link to determine whether the observed changes in policy support over time were greater in Canadian provinces with display bans than they were in those without bans. This approach accounted for the correlated nature of data within subjects across waves and permitted the assessment of the population averaged over the study period without requiring individuals to be present at each wave. All GEE models were specified via the exchangeable within-group correlation structure.

The observed changes in policy support were evaluated by testing the zone $\times$ wave interaction effect in the various GEE models. Coefficients of covariates of interest (predictor variables) such as noticing tobacco displays and signs in stores and key demographics in the models were exponentiated to estimate the OR of policy support. For each coefficient, the $p$ values and associated $95 \%$ CIs for the ORs are estimated via SEs.

\section{RESULTS \\ Support for a ban on POP advertising and displays in the five Canadian zones}

Policy support was greatest in zones 1 and 2 where there was early adoption of the display bans across the three waves, and lowest in zone 5 which was a late adopter, with just over half of smokers expressing support at each wave. Level of support for a display ban was fairly consistent between zones at wave 5, but relatively dispersed by wave 7 (see figure 1).

Similarly, support for a complete advertising ban was higher in zone 2 across the three waves and comparable in the remaining four zones as shown in table 2. Over two-thirds of smokers from zones 1 to 3 reported support for a ban on advertising at each wave. Additionally, level of support for a ban on advertising at POP was relatively consistent at wave 5 between zones but quite dispersed by wave 7 (figure 2).

Support for bans on advertising and displays in the five Canadian zones and their associations with intention to quit over time

Table 3 presents weighted GEE models for smokers who support advertising and display bans over time and the relationship this support has with quit intentions. Drawing from these results, the

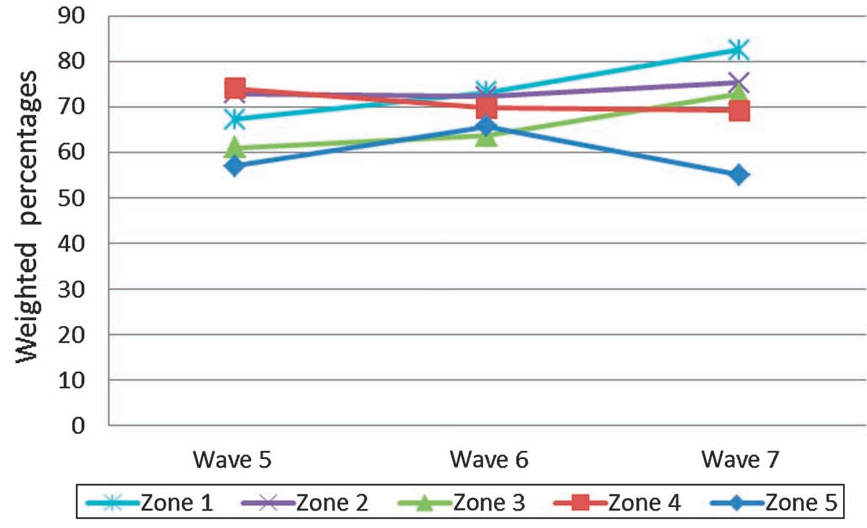

Figure 1 Support for a ban on point-of-purchase tobacco displays by waves and zones.

overall zone $\times$ wave interaction effect (not shown in table 3 ) indicated that support for a ban on displays was comparable across five Canadian zones over time $(p>0.05)$. Similarly, between-zone comparisons showed that support among smokers in Canada was comparable over the last three waves ( $p>0.05)$. However, smokers in Canada who intend to quit smoking were 2.32 times more likely to support a display ban over time $(p<0.0001)$. Smokers who noticed tobacco displays in stores were less supportive of a display ban over time $(\mathrm{OR}=0.73, \mathrm{p}=0.005)$.

Comparisons also showed that the overall zone $\times$ wave interaction across the five Canadian zones showed no overall difference among these jurisdictions in the levels of support for tobacco advertising ban over the three waves. Likewise, betweenzone comparisons showed that support for a ban on advertising was comparable over the study period ( $p>0.05)$. Comparisons with quit intentions revealed that smokers intending to quit smoking in Canada were 2.11 times more supportive of a ban on advertising than those who did not intend to quit. Smokers who noticed tobacco advertising in stores were less likely to support a ban on advertising $(\mathrm{OR}=0.78, \mathrm{p}=0.02)$.

\section{DISCUSSION}

Although denied the use of traditional marketing channels, the tobacco industry continues to use the retail environment to

Table 2 Support for a ban on point-of-purchase display and advertising (weighted frequencies by waves and zones)

\begin{tabular}{llll}
\hline & Wave 5 (\%) & Wave 6 (\%) & Wave 7 (\%) \\
\hline $\begin{array}{l}\text { Zone 1 } \\
\quad \text { Support display ban }\end{array}$ & $99(67.2)$ & $121(73.2)$ & $96(82.5)$ \\
$\quad$ Support ad ban & $99(68.0)$ & $114(68.6)$ & $91(75.7)$ \\
$\begin{array}{l}\text { Zone 2 } \\
\quad \text { Support display ban }\end{array}$ & $46(72.9)$ & $58(72.2)$ & $57(75.3)$ \\
$\quad$ Support ad ban & $49(75.0)$ & $58(75.1)$ & $64(85.7)$ \\
Zone 3 & & & \\
$\quad$ Support display ban & $881(61.0)$ & $858(63.6)$ & $836(72.8)$ \\
$\quad$ Support ad ban & $986(68.0)$ & $945(70.8)$ & $848(72.8)$ \\
Zone 4 & & & \\
$\quad$ Support display ban & $34(74.0)$ & $25(69.7)$ & $23(69.1)$ \\
$\quad$ Support ad ban & $32(69.3)$ & $25(60.7)$ & $24(67.3)$ \\
Zone 5 & & & \\
$\quad \begin{array}{l}\text { Support display ban } \\
\quad \text { Support ad ban }\end{array}$ & $23(56.9)$ & $35(65.7)$ & $22(55.0)$ \\
\hline
\end{tabular}

Zone 1, Saskatchewan, Manitoba and Prince Edward Island; zone 2, Nova Scotia; zone 3, Quebec, Ontario, Alberta and British Columbia; zone 4, New Brunswick; zone 5, Newfoundland and Labrador. 


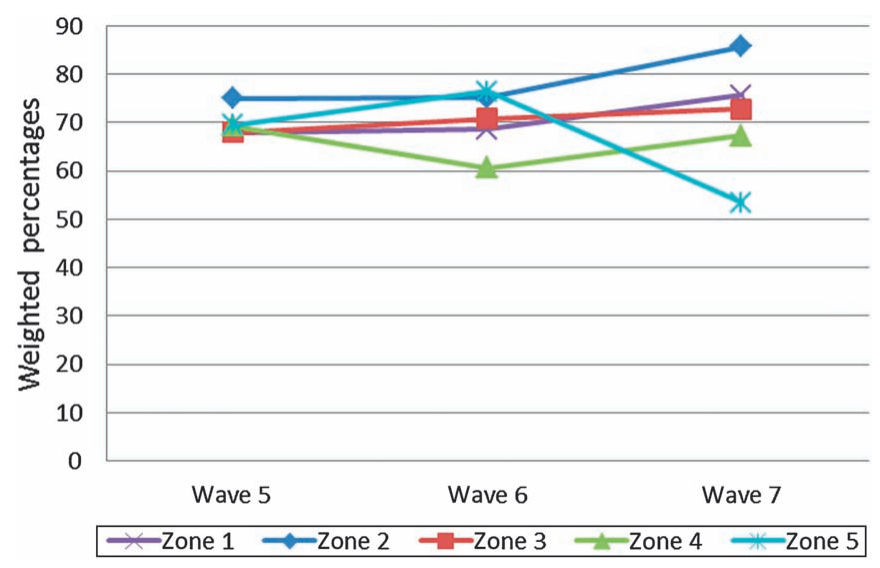

Figure 2 Support for a ban on point-of-purchase tobacco advertising by waves and zones.

market their goods. ${ }^{5}$ We investigated adult smokers' support for a complete ban on tobacco advertising and displays at POP across 10 Canadian provinces and how this relates to their intention to quit over time.

It was found that smokers in Canada had high levels of support for the removal of displays over the study period. This support, among those most likely to oppose such measures, has been found in respect to support for other tobacco control policies such as tobacco advertising and promotion bans, ${ }^{28} 29$ pictorial warning labels ${ }^{30}$ and smoke-free public places. ${ }^{31}$ The findings demonstrate the need for comprehensive bans on tobacco marketing, as included in Article 13 of the Framework Convention on Tobacco Control. ${ }^{32}$

Support was found to be greatest among smokers in Canadian provinces who were exposed to the policy at baseline, for example, at second follow-up, more than three-quarters of smokers in Saskatchewan, Manitoba and Prince Edward Island were supportive of a display ban compared with just over half of smokers in Newfoundland and Labrador, the only province not to ban displays until after the study period. There was, however, no significant difference in levels of support for a display ban across the 10 provinces and over the study period. It is possible that the comparable levels of support is indicative of the diffusion effect ${ }^{33-36}$ of the display ban (as a consequence of public campaign, lawsuit and debate surrounding its removal) from provinces such as Saskatchewan, Manitoba and Prince Edwards
Island, to those which had either a partial ban or no ban. Further research would be needed to confirm this, but past research has found diffusion of policy support for smoke-free legislation across geographically dispersed smokers. ${ }^{33} 3436$ We found no significant difference in reported levels of support for a ban on advertising at POP across the 10 provinces either.

Smokers in Canadian provinces who noticed tobacco displays and signs in stores were less likely to support a ban on advertising and displays. That smokers exposed to in-store tobacco promotion were less supportive of the ban suggests that the, perhaps reassuring, presence of these visual cues weakens support. Smokers who had intentions to quit smoking were supportive of a ban on tobacco advertising and displays. This support may, in part, be a consequence of not having to be exposed to attractive visual cues to smoke within the retail environment, with displays found to stimulate impulse purchase among those trying to quit. ${ }^{8}$

Despite the use of a longitudinal design, our study is not without limitations. Respondents are lost to attrition at followup, which can potentially skew findings. As the analyses were performed via weighted GEE, ${ }^{25} 26$ which allows these models to use all observations across the three waves, the potential effects of respondents lost to follow-up are minimised. There is also the possibility of differential bias between zones, as a result of the demand characteristics of the survey, which may have prompted socially desirable responding or may be influenced by personal experience or media coverage of policy implementation. Another potential limitation is the possibility of experiment-wise error as a result of the number of between-zone comparisons, that is, the likelihood of falsely rejecting the null hypothesis as a result of multiple comparisons. Finally, the no in-zone change in level of policy support over time may be due to lack of earlier data as well as the short study period.

In many countries, tobacco marketing at POP is one of the few remaining avenues for the tobacco industry to promote their products. Tobacco displays act as a potent marketing tool, ${ }^{5} 1213$ which normalise smoking and allow the tobacco industry to communicate with non-smokers, ex-smokers and established smokers. ${ }^{12} 3738$ That most smokers are supportive of banning the visible display of tobacco products in the retail environment, as they are with other tobacco control policies, should help persuade policy makers in other jurisdictions about the need to remove POP displays. Future research should assess the longer term impact of a display ban on smokers' support and

Table 3 GEE models* for support for a ban on POP display and advertising across the three waves and association with quit intentions and noticing tobacco displays and signs in stores

\begin{tabular}{|c|c|c|c|c|}
\hline & \multicolumn{2}{|l|}{ POP display ban } & \multicolumn{2}{|l|}{ POP advertising ban } \\
\hline & OR $(95 \% \mathrm{CI})$ & $\bar{p}$ Value & OR $(95 \% \mathrm{CI})$ & p Value \\
\hline \multicolumn{5}{|l|}{ Gender } \\
\hline Female versus male & 1.07 (0.09 to 1.27$)$ & 0.44 & $1.17(0.98$ to 1.39$)$ & 0.08 \\
\hline \multicolumn{5}{|l|}{ Age, years } \\
\hline $18-25$ vs $55+$ & 0.86 (0.61 to 1.21 ) & 0.39 & 0.93 (0.65 to 1.33 ) & 0.69 \\
\hline $25-39$ vs $55+$ & 0.95 (0.75 to 1.20$)$ & 0.66 & 0.94 (0.73 to 1.22$)$ & 0.63 \\
\hline $40-54$ vs $55+$ & $1.06(0.85$ to 1.30$)$ & 0.62 & 0.95 (0.77 to 1.87 ) & 0.68 \\
\hline Noticed display/signs & $0.73+(0.59$ to 0.91$)$ & 0.005 & $0.78 \neq(0.64$ to 0.95$)$ & 0.015 \\
\hline
\end{tabular}

The overall wave (time) and zone effect and their interaction and also between-zone comparisons for POP display and advertising ban (all not shown in table) were not significant ( $\mathrm{p}>0.05$ ) Design variable for wave (time) was coded: wave $5(0,0)$, wave $6(1,0)$ and wave $7(0,1)$.

*Each model is adjusted for age, sex, quit intentions, awareness of cigarette displays and signs in stores and shops as well as income, education, heaviness of smoking index and ethnicity, but these are not shown as they were not significant.

†Noticing tobacco signs in stores.

$\ddagger$ Noticing tobacco displays in stores.

POP, point-of-purchase. 


\section{What this paper adds}

- The tobacco industry is known to respond to restrictions on marketing by exploiting unregulated channels, such as at point-of-purchase.

- This paper shows that levels of support for a display ban at point-of-purchase were high and comparable across all 10 provinces in Canada, irrespective of whether tobacco displays within shops had been banned in each of these provinces.

- Support was lowest, however, in Newfoundland and Labrador, the only province not to introduce a ban on displays during the study period. Smokers intending to quit were more likely to support advertising and display bans over time.

if this support is linked to intention to quit, especially as a decline in exposure to displays at retail environment is anticipated to impact upon smoking cues and behaviour.

Funding The research was funded by grants from the US National Cancer Institute/NIH (from the Roswell Park Transdisciplinary Tobacco Use Research Center (TTURC), P50 CA111236 and from R01 CA100362), the Canadian Institutes for Health Research (57897), Robert Wood Johnson Foundation (045734), the Australian National Health and Medical Research Council (265903), Cancer Research UK (C312/A3726), the Australian Commonwealth Department of Health and Ageing, the Centre for Behavioural Research and Program Evaluation of the National Cancer Institute of Canada/Canadian Cancer Society and the Canadian Tobacco Control Research Initiative.

\section{Competing interests None.}

Ethics approval The study was approved by the Institutional Review Board or Research Ethics Board at the University of Stirling (Scotland), the Open University (UK), University of Waterloo (Canada), Roswell Park Cancer Institute (US), University of Illinois, Chicago (US), and The Cancer Council Victoria (Australia).

Contributors All authors included on this paper have fulfilled the criteria of authorship, ie, have contributed to the conception and design, acquisition of data analysis or interpretation of data as well as drafting or revising this article. Moreover, there is no one else who fulfils these criteria who has not been included as an author.

Provenance and peer review Not commissioned; externally peer reviewed.

\section{REFERENCES}

1. Wakefield M, Germain D, Durkin S, et al. An experimental study of effects on schoolchildren of exposure to point-of-sale cigarette advertising and pack displays. Health Educ Res 2006;21:338-47.

2. WHO. Report on the Global Tobacco Epidemic, 2008: The MPOWER Package. Geneva: World Health Organization, 2008.

3. WHO. Framework Convention on Tobacco Control, 2005. Geneva: World Health Organization, 2005

4. Davis R, Gilpin E, Loken B, et al. Influence of tobacco marketing on smoking behavior. In: Davis R, Gilpin E, Loken B, et al, eds. The Role of the Media in Promoting and Reducing Tobacco Use. Tobacco Control Monograph No.19. Bethesda, Maryland, USA: US Department of Health and Human Services, National Institutes of Health, National Cancer Institute, 2008:211-91.

5. Carter OB, Mills BW, Donovan RJ. The effect of retail cigarette pack displays on unplanned purchases: Results from immediate postpurchase interviews. Tob Control 2009;18:218-21.

6. Lovato C, Hsu HC, Sabiston CM, et al. Tobacco point-of-purchase marketing in school neighbourhoods and school smoking prevalence: A descriptive study. Can J Pub Health 2007:98:265-70.

7. Brown A, Moodie C. Tobacco marketing influences on smoking intentions via normative beliefs. Health Educ Res 2009;24:721-33.
8. Wakefield M, Germain D, Henriksen L. The effect of retail cigarette pack displays on impulse purchase. Addiction 2008;103:322-8.

9. Carter BL, Robinson JD, Lam CY, et al. A psychometric evaluation of cigarette stimuli used in a cue reactivity study. Nicotine Tob Res 2006:8:361-9.

10. Donovan RJ, Jancey J, Jones S. Tobacco point of sale advertising increases positive brand user imagery. Tob Control 2002:11:191-4.

11. Lovato C, Linn G, Stead L, et al. Impact of tobacco advertising and promotion on increasing adolescent smoking behaviors. Cochrane Database Syst Rev 2003;(4) CD003439.

12. Paynter J, Edwards R. The impact of tobacco promotion at the point of sale: a systematic review. Nicotine Tob Res 2009:11:322-8.

13. Thomson G, Hoek J, Edwards R, et al. Evidence and arguments on tobacco retail displays: marketing an addictive drug to children? N Z Med J 2008;121:87-98.

14. McNeill A, Lewis S, Quinn C, et al. Evaluation of the removal of point of sale tobacco displays in Ireland. Tob Control 2010;20:137-43.

15. Paynter J, Edwards R, Schluter PJ, et al. Point of sale tobacco displays and smoking amongst 14-15 year olds in New Zealand: cross sectional study. Tob Control 2009;18:268-74.

16. Health Canada. The Tobacco Act 1997, Ottawa, Ontario, Canada, 2010. http:// www.hc-sc.gc.ca/hc-ps/tobac-tabac/res/news-nouvelles/act-loi-eng.php

17. Quinn C, Lewis $S$, Edwards $\mathrm{R}$, et al. Economic evaluation of the removal of tobacco promotion in Ireland. Tob Control 2010:20:151-5.

18. Hickling JA, Miller CL. Cigarette pack and advertising displays at point of purchase: community demand for restrictions. Int J Consum Stud 2008;32:574-8.

19. Fong GT, Cummings KM, Borland R, et al. The conceptual framework of the international tobacco control (ITC) policy evaluation project. Tob Control 2006;15 (Suppl 3):iii3-11.

20. Binson D, Canchola JA, Catania JA. Random selection in a national telephone survey: a comparison of the Kish, next-birthday, and last-birthday methods. J Offic Stat 2000;16:53-60.

21. Thompson ME, Fong GT, Hammond D, et al. Methods of the International Tobacco Control (ITC) Four Country Survey. Tob Control 2006;15(suppl III):iii12-18.

22. de Vries $\mathbf{H}$, Mudde AN. Predicting stage transitions for smoking cessation applying the attitude social influence efficacy model. Psych Health 1998;13:369-85.

23. Prochaska J0, Redding CA, Evers K. The transtheoretical model and stages of change. In: Glanz K, Lewis FM, Rimer BK, eds. Health Behavior and Health Education: Theory, Research, and Practice. San Francisco, CA: Jossey-Bass, 1997:60-84

24. Borland $\mathbf{R}$, Yong HH, O'Connor RJ, et al. The reliability and predictive validity of the heaviness of smoking index and its two components: findings from the International Tobacco Control Four Country study. Nicotine Tob Res 2010;12(Suppl 1):S45-50.

25. Hardin JW, Hilbe JM. Generalized Estimating Equations. Boca Raton, FL: Chapman \& Hall/CRC, 2003

26. Liang KY, Zeger SL. Longitudinal data using generalized linear models. Biomet $J$ 1986:73:13-22.

27. Hedeker DR, Gibbons RD. Longitudinal Data Analysis. New York: Wiley, 2006

28. Marques-Vidal P, Melich-Cerveira J, Paccaud F, et al. Opinions on tobacco contro policies in Lausanne, Switzerland, 2003-2006. Prev Med 2010;51:193-4.

29. California Adult Tobacco Survey (CATS). Sacramento, CA: California Department of Public Health, 2007.

30. Fong GT, Hammond D, Hitchman SC. The impact of pictures on the effectiveness of tobacco warnings. Bull World Health Organ 2009;87:640-3

31. Hyland A, Hassan LM, Higbee $\mathrm{C}$, et al. The impact of smokefree legislation in Scotland: results from the Scottish ITC Scotland/UK longitudinal surveys. Eur J Pub Health 2009;19:198-205.

32. Harris F, MacKintosh AM, Anderson S, et al. Effects of the 2003 advertising/ promotion ban in the United Kingdom on awareness of tobacco marketing: findings from the International Tobacco Control (ITC) Four Country Survey. Tob Control 2006;15(Suppl 3):iii26-33.

33. Ferrence R. Diffusion theory and drug use. Addiction 2001;96:165-73.

34. Borland $\mathbf{R}$, Yong $\mathrm{HH}$, Cummings $\mathrm{KM}$, et al. Determinants and consequences of smoke-free homes: findings from the International Tobacco Control (ITC) Four Country Survey. Tob Control 2006;15(Suppl III):iii42-50.

35. Brown A, Moodie C, Hastings G. A longitudinal study of policy effect (smoke-free legislation) on smoking norms: ITC Scotland/United Kingdom. Nicotine Tob Res 2009:11:924-32

36. Eriksen MP, Cerak RL. The diffusion and impact of clean indoor air laws. Annu Rev Public Health 2008;29:171-85

37. Germain D, McCarthy M, Wakefield M. Smoker sensitivity to retail tobacco displays and quitting: a cohort study. Addiction 2009;105:159-63.

38. Hoek J, Gifford H, Pirikahu G, et al. How do tobacco retail displays affect cessation attempts? Findings from a qualitative study. Tob Control 2010;19:334-7. 